ORIGINAL ARTICLE

\title{
Fracture Resistance of Reattached Hydrated Fragment of Fractured Incisors
}

\author{
Minu Suresh ${ }^{1}$, Shanthala B Mallikarjun², George Babu ${ }^{3}$, Madakkattayil Abdu Zareena ${ }^{4}$
}

\begin{abstract}
Background and objectives: Fragment reattachment procedure provides conservative treatment option when an intact fractured fragment is available. Rewetting of fractured fragment before reattaching has shown better bond strength of attached fragment. Therefore, fracture resistance of reattached fractured fragment with hydration and without hydration was evaluated and compared.

Materials and methods: Ellis class II fracture was induced in selected and coded 60 extracted maxillary central incisors using a custom-madewise and assigned into group I and group II (without hydration and with hydration) and both the groups were further divided into two groups (1 week and 3 months). In group I, fractured fragments were reattached after bench-drying for 24 hours. In group II, fractured fragments were reattached after hydrating for 1 hour following bench-drying for 24 hours. Composite (Filtek Z350 XT, Universal Restorative, 3M ESPE) was used to reattach the fractured fragments. Reattached fractured fragments were stored in artificial saliva for 1 week and 3 months and subjected to fracture resistance test using Universal Testing Machine. The data obtained were tabulated and statistically analyzed.

Results: Fracture resistance in hydration samples was higher than without hydration at the end of 1 week and 3 months statistically. Fracture resistance of fractured fragment at the end of 3 months was higher in both with hydration and without hydration but was not significant with hydration.

Conclusion: Hydration of fractured fragment before reattachment procedure has shown better fracture resistance and improved further after storing in artificial saliva for 3 months.

Keywords: Dehydration, Fracture resistance, Fragment reattachment, Hydration.

International Journal of Clinical Pediatric Dentistry (2020): 10.5005/jp-journals-10005-1819
\end{abstract}

\section{INTRODUCTION}

In dental clinics, treatment approaches followed in management of dental trauma is crucial as they occur frequently in daily life. ${ }^{1}$ Dental trauma results either as crown fracture or avulsion and with or without pulpal involvement or bone fracture. ${ }^{2}$ Crown fractures of the anterior teeth have been found to have a profound influence on social and psychological well-being of a child/adult patient. Besides minor luxation injuries such as concussion or loosening of the teeth, crown fractures are the most common consequences of dental trauma. ${ }^{3}$ In all, 18 to $22 \%$ of crown fractures are of permanent incisors out of which 28 to $44 \%$ are simple fracture (enamel + dentin) and 11-15\% are complex fracture (enamel + dentin + pulp). Maxillary central incisors are affected in majority up to $96 \%{ }^{4}$

Reattachment of the fractured fragment in simple crown fracture would be a preferred treatment choice when the biological width of the fractured fragment is maintained and available for reattachment. ${ }^{5}$ Fractured fragment reattachment has the advantage of being conservative, esthetically acceptable, and cost effective when compared to alternate restorative options, such as resin-based composite restoration or full-coverage crown. ${ }^{5}$ Reattachment of a fractured fragment can provide adequate adaptation to the remnant tooth structure in the oral cavity as a autogenous bonding technique and can be an ideal choice of treatment. ${ }^{6}$

Chosack and Eidelman first described autogenous bonding in 1964 and has been used widely since then. The retention period of the reattached fractured fragment depends on the techniques followed in preparation of the fractured tooth and its fragment,

\footnotetext{
${ }^{1-4}$ Department of Pediatric Dentistry, Coorg Institute of Dental Sciences, KK Campus, Karnataka, India

Corresponding Author: Minu Suresh, Department of Pediatric Dentistry, Coorg Institute of Dental Sciences, KK Campus, Karnataka, India, Phone: +91 9448378367, e-mail: drminusuresh91@gmail.com

How to cite this article: Suresh M, Mallikarjun SB, Babu G, et al. Fracture Resistance of Reattached Hydrated Fragment of Fractured Incisors. Int J Clin Pediatr Dent 2020;13(5):476-480.

Source of support: Nil

Conflict of interest: None
}

bonding agents, composite materials used, and storage of fractured fragment. Immediately after a trauma, the fractured fragment is exposed to the external environment and begins to dehydrate, decreasing the potential bond strength between the fragment and the remaining structure. ${ }^{6}$ Strength and esthetics are the critical end results of a successful treatment. Dehydration often changes the color of the fragment, creating a mismatch with the tooth remnant. Therefore, the fragment should be hydrated by immersing in distilled water for a duration of minimum 30 minutes to maximum 24 hours before reattachment procedure. ${ }^{6}$

Previous investigations have shown an inverse relation in fracture strength and dehydration time as it increases from 5 seconds to 24 hours. Rewetting/hydration of the fractured fragment for at least 24 hours or 30 minutes has been demonstrated to be sufficient even after either 24 hours or 48 hours of drying. ${ }^{7}$

(-) The Author(s). 2020 Open Access This article is distributed under the terms of the Creative Commons Attribution 4.0 International License (https://creativecommons. org/licenses/by-nc/4.0/), which permits unrestricted use, distribution, and non-commercial reproduction in any medium, provided you give appropriate credit to the original author(s) and the source, provide a link to the Creative Commons license, and indicate if changes were made. The Creative Commons Public Domain Dedication waiver (http://creativecommons.org/publicdomain/zero/1.0/) applies to the data made available in this article, unless otherwise stated. 
Keeping the fractured part in a wet/moist environment before reattaching has been reported to be advantageous in the successful outcome of the reattachment procedure, as most of the time patient reports for reattachment procedure with the fractured fragment at a varying time lapsed from the time of trauma (that is, from few minutes to days). In prolonged time from the time of trauma to the reattachment procedure, the fractured fragment may lose its moisture. $^{8}$

Hydration maintains the vitality and original esthetic appearance of the fractured fragment. ${ }^{9}$ Hydration of the fractured fragment should be considered primarily in the reattachment procedure. ${ }^{10}$ The longer fragment remains dehydrated, but adhesion will be weaker. Rewetting of dried tooth fragments longer than 1 hour appeared to worsen the adhesive bond with the remaining tooth structure. A fractured tooth fragment that is dried out must be rewetted before trying to bond it to the remaining tooth structure. ${ }^{11}$

Thus, the research hypothesis stated was rewetting/hydration of fractured fragment before reattachment would improve fracture resistance. In the present study, comparative evaluation of fracture resistance of dehydrated and hydrated fracture fragment was done.

\section{Materials and Methods}

After obtaining the ethical clearance from the institutional review board, 60 permanent central incisors extracted for therapeutic purpose were used in this study. Extracted teeth were washed in running water, cleaned from debris and calculus, and stored in artificial saliva until further use. All the samples were examined under $10 \times$ magnification using a stereomicroscope to check for any signs of fracture or craze line before inducing fracture.

\section{Inducing Ellis Class II Fracture}

Ellis class II fracture was induced in all the prepared teeth samples with the help of two custom-made blades mounted on

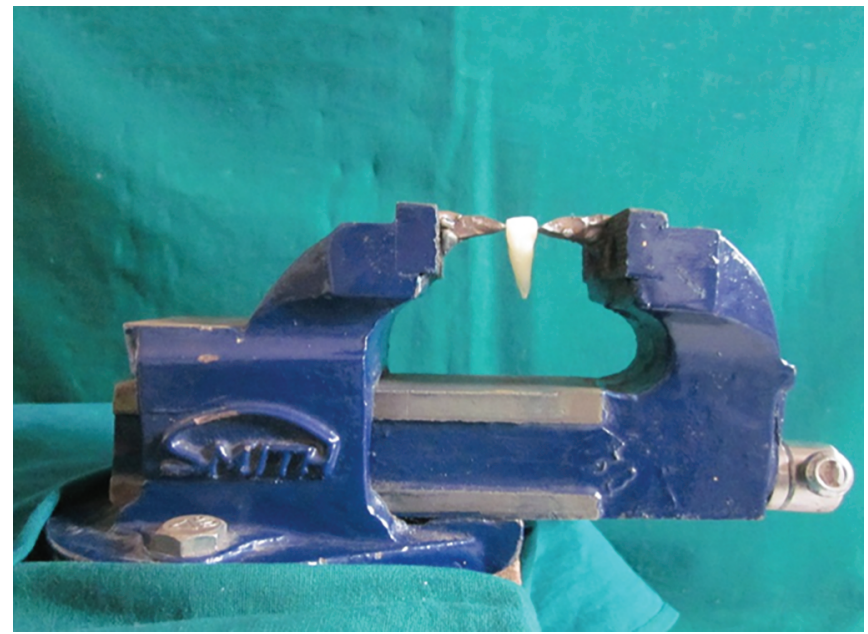

Fig. 1: Custom-made blade mounted on a vise to induce Ellis class II fracture a vise. Fracture was induced transversely by applying the force on the proximal surfaces of the incisors $3 \mathrm{~mm}$ below the incisal edge with the help of the sharp blades that were mounted on either side of the vise (Fig. 1). In any tooth, if Ellis class II fracture was unable to achieve, they were replaced with the other tooth.

The fractured fragment of the tooth (Fig. 2) and its counterpart were stored in artificial saliva in an individual number coded (1-60) container to prevent contamination of the sample.

The number-coded samples were divided into two equal groups:

Group I-Without hydration of fractured fragment $(n=30)$, i.e., from 1 to 30

Group II-With hydration of fractured fragment $(n=30)$, i.e., from 31 to 60

They were further divided equally into two groups for different periods of time i.e., 1 week and 3 months.

\section{Bench-drying and Hydration of the Fractured Fragment}

Fractured fragment from both the groups were removed from artificial saliva and allowed to bench dry for 24 hours. Samples from group I were reattached without hydration. Samples from group II were subjected to one hour of hydration before reattachment.

\section{Reattachment of Fractured Teeth}

Composite (Filtek Z350 XT, Universal Restorative, 3M ESPE) was used to restore the fractured teeth fragments.

The fracture resistance of reattached samples in both the groups with hydration and without was evaluated at the end of 1 week and 3 months. The force required to fracture the bonded fragments were recorded in Newtons using the Universal Testing Machine.

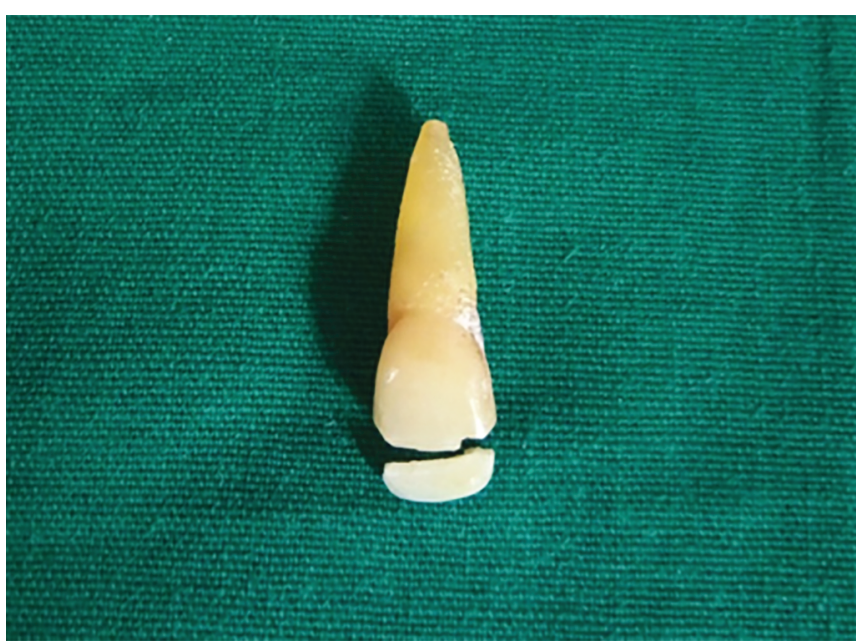

Fig. 2: Induced Ellis class II fracture in the selected sample 


\section{Methodology Flowchart}

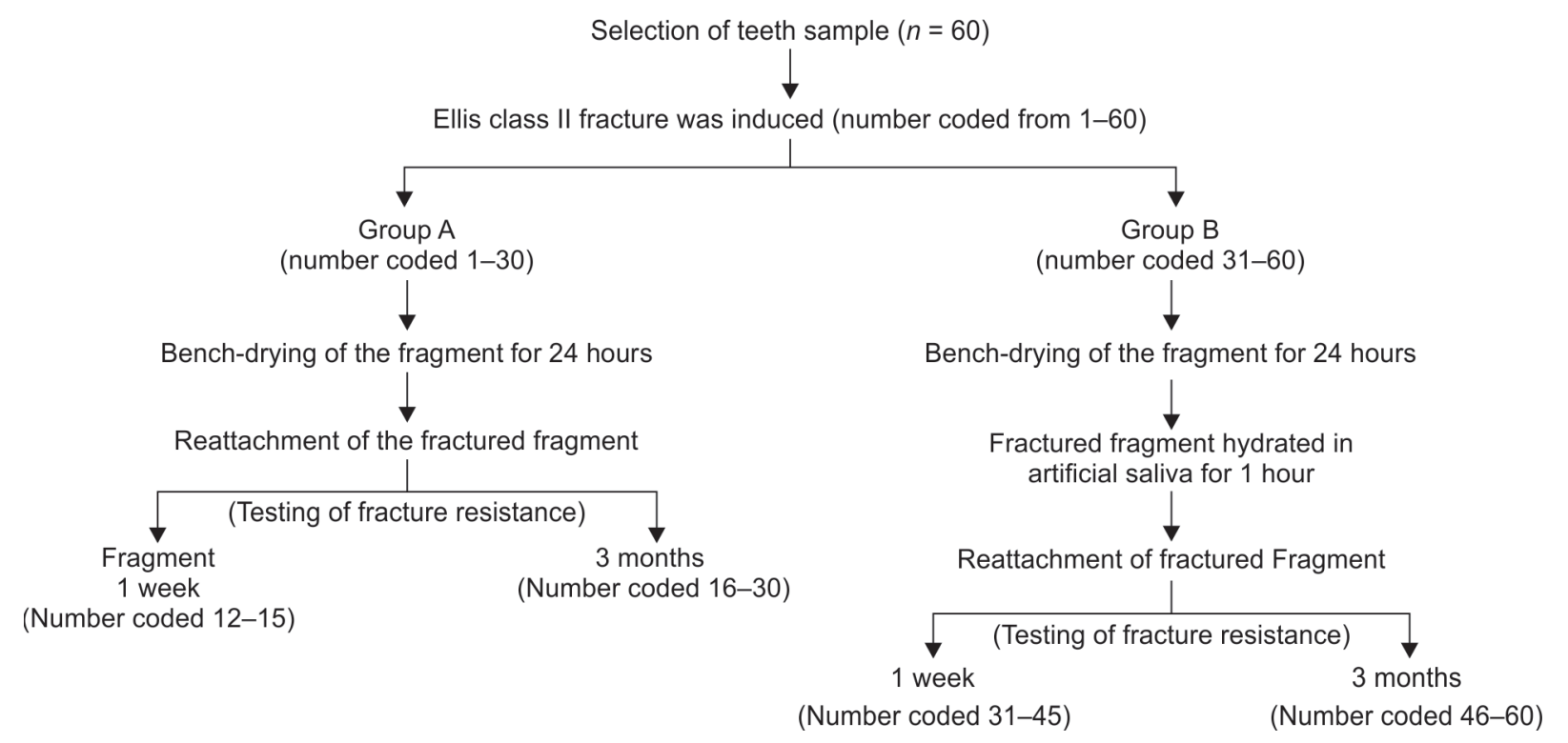

\section{Results}

The average force required to fracture the reattached fragments in without hydration after 1 week was $153.3 \mathrm{~N}$ and after 3 months was $173.3 \mathrm{~N}$ and with hydration after 1 week was $322.6 \mathrm{~N}$ and after 3 months was $336.6 \mathrm{~N}$ (Table 1 and Fig. 3)

Paired $t$ test without hydration between 1 week and 3 months was found to be significant ( $p$ value $=0.001085$ ) and with hydration between 1 week and 3 months was found to be not significant ( $p$ value $=0.1709)$ (Table 2$)$.

Two-sample $t$ test comparison after 1 week without hydration and with hydration was found to be significant ( $p$ value $=<2.2 \times$ $10^{-16}$ ) and between after 3 months without hydration and with hydration was also found to be significant ( $p$ value $=<2.2 \times 10^{-16}$ ) (Table 2).

\section{Discussion}

Fracture resistance of the re-attached fragment in a reattachment procedure depends on the preparation of the fragments and the type of composites used. Placement of an internal groove and use of resin composite restoration have shown fracture strength similar to sound tooth structure, whereas Neslihan et al. have demonstrated that placement of any kind of preparation would not improve the fracture strength of reattached fragment. ${ }^{12}$ A conventional total-etch adhesive system on fragment reattachment in fractured teeth was suggested instead of selfetch adhesives systems. ${ }^{13}$

Hydration of the fractured fragment influences the fracture resistance of the reattached fragment. In reattachment procedure, hydration of fractured fragment along with hydrophilic characteristic of adhesive systems ensures adequate bond strength., ${ }^{9,14}$

Hydrating dried dentin for 2 seconds using moisturizing agent was inadequate, to moisturize the collapsed collagen fibers, and indicated decreased fracture strength. ${ }^{15}$

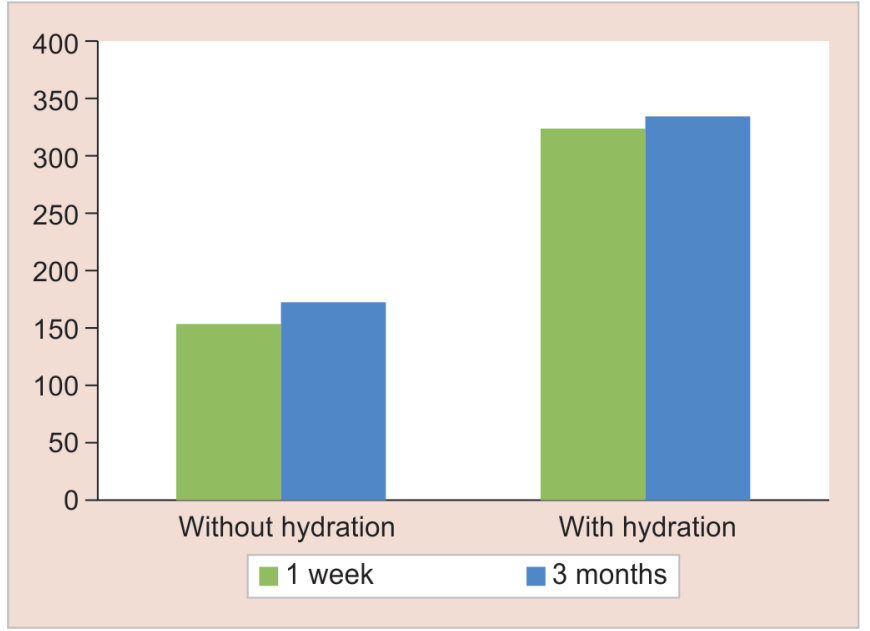

Fig. 3: Bar diagram showing the mean fracture resistance values

Recovery in bond strength was observed when rehydrating dry fragments in water for 30 minutes 24 hours prior to bonding. ${ }^{15,16}$

Review of literature on hydration and dehydration of the fractured fragments without using any preparation of the fractured fragment and bonding by total-etch adhesive systems using Composite, Filtek Z350 XT, Universal Restorative, 3M ESPE was sparse. Hence, a comparative evaluation on the hydration of fractured fragment's and its effect on fracture resistance after 1 week and 3 months was observed. 12,13,17

Fracture resistance of reattached fragments stored in saline and milk has demonstrated greater fracture resistance on comparison without any hydration (dried) ${ }^{18}$ Shirani et al. have shown that maintaining fractured parts in milk and saliva environments can increase the force required force fracturing reattached teeth. ${ }^{8}$ Shirani et al. compared the effect of various dry and wet storage 
Table 1: The force required to fracture the reattached tooth fragments

\begin{tabular}{cccccc}
\hline & \multicolumn{2}{c}{ Group I (without hydration) } & & \multicolumn{2}{c}{ Group II (with hydration) } \\
\cline { 2 - 3 } \cline { 5 - 6 } & 1 Week & 3 Months & & 1 Week & 3 Months \\
\hline 1 & $150 \mathrm{~N}$ & $170 \mathrm{~N}$ & $310 \mathrm{~N}$ & $290 \mathrm{~N}$ \\
2 & $160 \mathrm{~N}$ & $180 \mathrm{~N}$ & $300 \mathrm{~N}$ & $290 \mathrm{~N}$ \\
3 & $170 \mathrm{~N}$ & $160 \mathrm{~N}$ & $340 \mathrm{~N}$ & $300 \mathrm{~N}$ \\
4 & $150 \mathrm{~N}$ & $190 \mathrm{~N}$ & $290 \mathrm{~N}$ & $370 \mathrm{~N}$ \\
5 & $140 \mathrm{~N}$ & $170 \mathrm{~N}$ & $290 \mathrm{~N}$ & $370 \mathrm{~N}$ \\
6 & $130 \mathrm{~N}$ & $170 \mathrm{~N}$ & $330 \mathrm{~N}$ & $390 \mathrm{~N}$ \\
7 & $160 \mathrm{~N}$ & $160 \mathrm{~N}$ & $330 \mathrm{~N}$ & $310 \mathrm{~N}$ \\
8 & $160 \mathrm{~N}$ & $200 \mathrm{~N}$ & $310 \mathrm{~N}$ & $340 \mathrm{~N}$ \\
9 & $170 \mathrm{~N}$ & $170 \mathrm{~N}$ & $330 \mathrm{~N}$ & $310 \mathrm{~N}$ \\
10 & $130 \mathrm{~N}$ & $180 \mathrm{~N}$ & $310 \mathrm{~N}$ & $310 \mathrm{~N}$ \\
11 & $150 \mathrm{~N}$ & $160 \mathrm{~N}$ & $340 \mathrm{~N}$ & $330 \mathrm{~N}$ \\
12 & $150 \mathrm{~N}$ & $190 \mathrm{~N}$ & $350 \mathrm{~N}$ & $370 \mathrm{~N}$ \\
13 & $160 \mathrm{~N}$ & $170 \mathrm{~N}$ & $330 \mathrm{~N}$ & $370 \mathrm{~N}$ \\
14 & $160 \mathrm{~N}$ & $170 \mathrm{~N}$ & $340 \mathrm{~N}$ & $360 \mathrm{~N}$ \\
15 & $160 \mathrm{~N}$ & $160 \mathrm{~N}$ & $340 \mathrm{~N}$ & $340 \mathrm{~N}$ \\
Average & $153.3 \mathrm{~N}$ & $173.3 \mathrm{~N}$ & $322.6 \mathrm{~N}$ & $336.6 \mathrm{~N}$ \\
\hline
\end{tabular}

Table 2: Descriptive statistics for the comparison between fracture resistance in the two groups

\begin{tabular}{|c|c|c|c|c|c|c|}
\hline & \multicolumn{3}{|c|}{ Group I } & \multicolumn{3}{|c|}{ Group II } \\
\hline & \multicolumn{2}{|c|}{1 Week (N) } & 3 Months (N) & \multicolumn{2}{|c|}{1 Week $(N)$} & 3 Months (N) \\
\hline Mean & \multicolumn{2}{|c|}{153.333} & 173.3333 & \multicolumn{2}{|c|}{322.6667} & 336.6667 \\
\hline $\begin{array}{l}\text { Standard } \\
\text { deviation }\end{array}$ & \multicolumn{2}{|c|}{12.34427} & 12.34427 & \multicolumn{2}{|c|}{19.52327} & 33.44467 \\
\hline Group & & Test & t value & $d f$ & $p$ value & Conclusion \\
\hline $\begin{array}{l}\text { Without hy } \\
\text { between } \\
1 \text { week and } \\
3 \text { months }\end{array}$ & dration & $\begin{array}{l}\text { Paired } \\
t \text { test }\end{array}$ & 4.0988 & 14 & 0.001085 & $\mathrm{~S}$ \\
\hline $\begin{array}{l}\text { With hydrat } \\
\text { between } 1 \\
\text { and } 3 \text { mont }\end{array}$ & $\begin{array}{l}\text { ion } \\
\text { veek } \\
\text { hs }\end{array}$ & $\begin{array}{l}\text { Paired } \\
t \text { test }\end{array}$ & 1.4433 & 14 & 0.1709 & NS \\
\hline $\begin{array}{l}\text { After } 1 \text { wee } \\
\text { out hydrati } \\
\text { with hydrat }\end{array}$ & $\begin{array}{l}\text { with- } \\
\text { on and } \\
\text { on }\end{array}$ & $\begin{array}{l}\text { Two- } \\
\text { sample } \\
t \text { test }\end{array}$ & 28.474 & 28 & $\begin{array}{l}<2.2 \times \\
10^{-16}\end{array}$ & $S$ \\
\hline $\begin{array}{l}\text { After } 3 \text { mon } \\
\text { without hyc } \\
\text { and with } \\
\text { hydration. }\end{array}$ & $\begin{array}{l}\text { ths } \\
\text { Iration }\end{array}$ & $\begin{array}{l}\text { Two- } \\
\text { sample } \\
t \text { test }\end{array}$ & 17.708 & 28 & $\begin{array}{l}<2.2 \times \\
10^{-16}\end{array}$ & S \\
\hline
\end{tabular}

periods on the reattached fragment's bond to the tooth and concluded that 24-hour rehydration of the tooth fragment before treatment seems to salvage enough moisture to result in an increase in reattachment strength. ${ }^{10}$

Thus, multiple factors are involved in achieving required fracture resistance of reattached fragment. In the present study, fracture fragment hydrated before reattachment was found to have higher fracture resistance when compared to fracture fragments reattached without hydration. This is similar to the results of studies that have shown fragment discoloration resulting from the dehydration of fragment and decreased bond strength between the tooth remained and fragment. ${ }^{10,11,18}$

Accordingly, it is recommended to maintain the fracture fragment in moist environment until its reattachment to prevent the consequent effects. ${ }^{19,20}$

Shirani $\mathrm{F}$ et al. observed discoloration in fractured fragment because of losing its moisture, but after 1 month of reattachment, the fragment had regained some of the original color and translucency, and after 1 year, the reattached fragment had satisfactory esthetics and excellent function. ${ }^{8}$ In the present study, storage of reattached fractured fragment in artificial saliva for 3 months in both the dehydrated and the hydrated samples demonstrated higher fracture resistance suggesting prolonged duration period of hydration restores the lost moisture and reduces the consequences of the dehydration such as decreased bonding strength and aesthetic ${ }^{18,21}$

The findings from this study are in accordance with the observation of Yucal et al. The clinical study of reattached fractured tooth and its follow-up for 2 years exhibited initially encountered color disharmony was resolved significantly on its own within 12 months after reattachment of the fragment.

In conclusion the hydration of fractured fragments before the reattachment procedure shows improved fracture resistance. Fragment reattachment can be effectively used to treat fractured teeth in children and adolescents.

\section{References}

1. Tuzuner $T$, Turgut $S$, Ozen $B$, et al. Storing tooth segments for pptimal esthetics. J Clin Pediat Dentis 2016;40(2):113-117. DOI: 10.17796/10534628-40.2.113.

2. Pavone $A$, Ghassemian M, Mancini M, et al. Autogenous tooth fragment adhesive reattachment for a complicated crown root fracture: two interdisciplinary case reports. Case Rep Dent 2016;2016:1-7.

3. Maitin N, Maitin S, Rastogi K, et al. Allogenous tooth fragment reattachment. Case Reports 2013(jul10 1):bcr2013010298bcr2013010298.

4. Divakar HD, Nayak M, Shetty RA. Changing concepts in fracture reattachment of teeth-a case series. Endodontology 2007;2:27-35.

5. Macedo GV, Diaz PI, de O Fernandes CA, et al. Reattachment of anterior teeth fragments: a conservative approach. J Esthet Restor Dent 2008;20(1):5-18. DOI: 10.1111/j.1708-8240.2008.00142.x.

6. Monteiro MJF, Cohen-Carneiro F, Tino GD, et al. Adhesive reattachment rehabilitating a nonvital central incisor with a complicated crownroot fracture: 1-year follow-up. Gen Dent 2015;63:e12-e17.

7. Terry DA. Adhesive reattachment of a tooth fragment: the biological restoration. Pr Proced Aesthet Dent 2003;15(5):403-409.

8. Shirani F, Tahririan D, Malekipour M, et al. Effect of storage environment on the bond strength of reattachment of crown fragments to fractured teeth. J Conservat Dentis 2011;14(3):269. DOI: 10.4103/0972-0707.85813.

9. Capp Cl, Roda MI, Tamaki R, et al. Reattachment of rehydrated dental fragment using two techniques. Dent Traumatol 2009;25(1):95-99. DOI: 10.1111/j.1600-9657.2008.00715.x.

10. Shirani F, Malekipour M, Manesh VS, et al. Hydration and dehydration periods of crown fragments prior to reattachment. Oper Dent 2012;37(5):501-508. DOI: 10.2341/10-130-L.

11. Monika $\mathrm{H}$, Mariana $\mathrm{P}$, Pop $\mathrm{M}$, et al. Influence of dentin dryness on the adhesive strength of reattached tooth fragments. An in vitro study. Acta Medica Marisiensis 2012;58(6):405-408.

12. Arhun N, Ungor M. Re-attachment of a fractured tooth: a case report. Dent Traumatol 2007;23(5):322-326. DOI: 10.1111/j.16009657.2006.00462.x. 
13. Bruschi-Alonso RC, Alonso RCB, Correr GM, et al. Reattachment of anterior fractured teeth: effect of materials and techniques on impact strength. Dent Traumatol 2010;26(4):315-322. DOI: 10.1111/j.16009657.2010.00906.x.

14. Singhal $R$, Pathak A. Comparison of the fracture resistance of reattached incisor tooth fragments using 4 different materials. J Indian Soc Pedod Prev Dent 2012;30(4):310. DOI: 10.4103/09704388.108927.

15. Farik B, Munksgaard EC, Kreiborg S, et al. Adhesive bonding of fragmented anterior teeth. Endod Dent Traumatol 1998;14(3):119-123. DOI: 10.1111/j.1600-9657.1998.tb00823.x.

16. Farik B, Munksgaard EC, Andreasen JO, et al. Drying and rewetting anterior crown fragments prior to bonding. Endod Dent Traumatol 1999;5(3):113-116. DOI: 10.1111/j.1600-9657.1999.tb00766.x.
17. Sapna CM, Kumar R, Rajan RR, et al. Uncomplicated crown fracture: a biological management option. Int J Appl Dent Sci 2014;1(1):15-17.

18. Sharmin D, Thomas E. Evaluation of the effect of storage medium on fragment reattachment. Dent Traumatol 2012;29(2):99-102. DOI: 10.1111/j.1600-9657.2012.01143.x.

19. Andreasen FM, Noren JG, Andreasen JO, et al. Long-term survival of fragment bonding in the treatment of fractured crown: a multicenter clinical study. Quintessence Int 1995;26:669-681.

20. Yilmaz Y, Guler C, Sahin H, et al. Evaluation of tooth-fragment reattachment: a clinical and laboratory study. Dent Traumatol 2010;26(4):308-314. DOI: 10.1111/j.1600-9657.2010.00907.x.

21. Limaye N, Prabhakar A, Yavagal C, et al. Effect of storage media on fracture resistance of reattached tooth fragments using $\mathrm{G}$-aenial Universal flo. J Conservat Dentis 2016;19(3):250. DOI: 10.4103/0972 0707.181942 . 